\title{
Review of: "An essential vesicular-trafficking phospholipase mediates neutral lipid synthesis and contributes to hemozoin formation in Plasmodium falciparum"
}

\author{
Kildare Miranda ${ }^{1}$, Camila Wendt \\ 1 Universidade Federal do Rio de Janeiro
}

Potential competing interests: The author(s) declared that no potential competing interests exist.

\section{Functional role of lipid metabolism in hemozoin nucleation}

Malaria remains as a major health problem, being responsible for more than 200 million cases and over 400 thousand deaths in 2019 [1]. Significant efforts have been made to develop effective prevention strategies and to improve the effectiveness of antimalarial drugs currently used. However, achieving effective intervention strategies depends on a deep knowledge on parasite biology, making the study of a model as complex as Plasmodium a fertile ground for the discovery of novel host-parasite interaction mechanisms. As the main clinical aspects of the disease in humans are directedly related to parasite development inside erythrocytes [2], understanding the mechanisms by which the parasite modulates host cell structure and metabolism is crucial. Part of these mechanisms involves the assembly of an elaborated exomembrane system $[3,4]$ and the uptake of large amounts of hemoglobin from host cell cytoplasm [57]. Degradation of internalized hemoglobin inside the food vacuole, releasing aminoacids and conversion of free heme into hemozoin crystals or 'malarial pigment' are amongst the most relevant topics on malaria biology [8].

Hemozoin is a unique structure so far described only in malaria parasites and blood-feeding organisms [912]. This crystal plays multiple roles on malaria biology, being used for more than a century as a biomarker for malaria detection in blood smears. Hemozoin may potentially modulate the host immune system [9, $13,14]$ and has been shown to remain in the host body for long periods of time [15]. Crystallization mechanisms also stand as important drug targets, since hemozoin synthesis is vital for parasite development inside erythrocytes. In this regard, pharmacological inhibition of hemoglobin catabolism and hemozoin nucleation have proven efficient methods to clear Plasmodium spp. infection in the vertebrate host $[8,10]$. Resistance to antimalarial drugs, however, remains as a major problem. Understanding the molecular, biochemical and structural basis of such drug targets is therefore of paramount importance for the development of more efficient therapies. 
Many groups have worked on the characterization of hemozoin crystal structure and its synthetic analogue, $\beta$-hematin [16-20]. Yet, the precise mechanisms underlying hemozoin formation remains elusive. Nevertheless, it is widely recognized that a nucleation center is required to initiate the process, although different hypothesis have been postulated manly based on the role of proteins [21-23] or lipids [24-27] to promote heme dimerization and crystal propagation.

n this regard, the recent work developed by Asad et al., comes at the right time, shedding light on the importance of lipid metabolism for hemozoin formation in Plasmodium falciparum. In their recent work, the authors characterized the functional role of the parasite lysophospholipase, PfLPL1, on the synthesis of neutral lipids and its importance for hemozoin nucleation during its intra erythrocytic development. Fluorescence microscopy and transmission electron microscopy approaches revealed that PfLPL1 containing vesicles traffic from parasite periphery towards vicinity of food vacuole, potentially contributing to the regulation of hemozoin formation. Knock-down of PfLPL1 resulted in the reduction of food vacuole associated neutral lipids and disrupted hemozoin formation within the parasite. The phenotype observed in knocked down parasites was very interesting and corroborates previous observations that suggested the importance of lipids on hemozoin formation. It is an important finding, since previous attempts to disturb proteins considered to be involved on hemozoin nucleation process were not that effective. P. falciparum mutants that lack histidine-rich protein II (HRPII), for example, showed no perturbation to hemozoin growth or heme crystallization [28]. Molecular attempts to disturb another proteins relate to hemozoin formation, heme detoxification protein (HDP), have so far been unsuccessful [21].

Asad et al., work is interesting and definitely worth of reading for the malaria community. In addition to the important contribution to the understanding of lipid metabolism on malaria parasites, it provides a clear link between lipid catabolism and hemozoin nucleation pathway. Recent works have shown that phospholipases are essential for $P$. falciparum transition from the asexual blood stages to gametocytes [29], for gametogenesis fertilization [30] and for schizogonic asexual division [31], highlighting the importance of membrane remodeling by phospholipase for parasite development and the contribution of the findings by Asad et al., for malaria biology. Phospholipases are encoded by 22 different genes in $P$. falciparum [32] and their enzymatic activities, location and expression patterns are nevertheless not well characterized. Further studies on the role of phospholipases will definitely provide novel information on lipid metabolism in malaria parasites, perhaps bringing new insights on parasite survival mechanisms.

1. WHO. World Malaria Report 2020. 2020. https://www.who.int/publications-detail/world-malaria-report2020.

2. Cowman AF, Healer J, Marapana D, Marsh K. Malaria: Biology and Disease. Cell. 2016;167:610-24. 
doi:10.1016/j.cell.2016.07.055.

3. Sherling ES, Ooij C Van. Host cell remodeling by pathogens : the exomembrane system in Plasmodiuminfected erythrocytes. 2016; April:701-21.

4. de Koning-Ward TF, Dixon MWA, Tilley L, Gilson PR. Plasmodium species: Master renovators of their host cells. Nat Rev Microbiol. 2016;14:494-507. doi:10.1038/nrmicro.2016.79.

5. Goldberg DE. Hemoglobin degradation in the malaria parasite Plasmodium falciparum: an ordered pathway in a unique organelle. Proc Natl Acad Sci USA. 1990;87:2931-5.

6. Wendt C, Rachid R, Souza W De, Miranda K. Electron tomography characterization of hemoglobin uptake in Plasmodium chabaudi reveals a stage-dependent mechanism for food vacuole morphogenesis. J Struct Biol. 2016;194:171-9. doi:10.1016/j.jsb.2016.02.014.

7. Abu Bakar N, Klonis N, Hanssen E, Chan C, Tilley L. Digestive-vacuole genesis and endocytic processes in the early intraerythrocytic stages of Plasmodium falciparum. J Cell Sci. 2010;123:441-50.

8. Sigala PA, Goldberg DE. The peculiarities and paradoxes of Plasmodium heme metabolism. Annu Rev Microbiol. 2014;68:259-78. doi:10.1146/annurev-micro-091313-103537.

9. Coronado LM, Nadovich CT, Spadafora C. Malarial hemozoin: From target to tool. Biochim Biophys Acta Gen Subj. 2014;1840:2032-41. doi:10.1016/j.bbagen.2014.02.009.

10. Hempelmann E. Hemozoin biocrystallization in Plasmodium falciparum and the antimalarial activity of crystallization inhibitors. Parasitol Res. 2007;100:671-6.

11. Oliveira MF, Kycia SW, Gomez A, Kosar AJ, Bohle DS, Hempelmann E, et al. Structural and morphological characterization of hemozoin produced by Schistosoma mansoni and Rhodnius prolixus. FEBS Lett. 2005;579:6010-6. doi:10.1016/j.febslet.2005.09.035.

12. Oliveira MF, Silva JR, Dansa-Petretski M, de Souza W, Lins U, Braga CM, et al. Haem detoxification by an insect. Nature. 1999;400:517-8. doi:10.1038/22910.

13. Boura M, Frita R, Góis A, Carvalho T, Hänscheid T. The hemozoin conundrum: Is malaria pigment immune-activating, inhibiting, or simply a bystander? Trends Parasitol. 2013;29:469-76.

14. Shio MT, Kassa FA, Bellemare MJ, Olivier M. Innate inflammatory response to the malarial pigment hemozoin. Microbes and Infection. 2010;12:889-99.

15. Mota MM, Jarra W, Hirst E, Pradeep K, Holder A a, Patnaik PK. Plasmodium chabaudi infected erythrocytes adhere to CD36 and bind to microvascular endothelial cells in an organ-specific way. Infect Immun. 2000;68:4135-44.

16. Egan TJ. Physico-chemical aspects of hemozoin (malaria pigment) structure and formation. J Inorg Biochem. 2002;91:19-26.

17. Pagola S, Stephens PW, Bohle DS, Kosar a D, Madsen SK. The structure of malaria pigment betahaematin. Nature. 2000;404:307-10.

18. Noland GS, Briones N, Sullivan DJ. The shape and size of hemozoin crystals distinguishes diverse Plasmodium species. Mol Biochem Parasitol. 2003;130:91-9. doi:10.1016/S0166-6851(03)00163-4. 19. Olafson KN, Ketchum MA, Rimer JD, Vekilov PG. Mechanisms of hematin crystallization and inhibition by 
the antimalarial drug chloroquine. Proc Natl Acad Sci U S A. 2015;112:4946-51.

doi:10.1073/pnas.1501023112.

20. Wendt C, Souza W de, Pinheiro A, Silva L, Pinheiro AA de S, Gauvin R, et al. High-Resolution Electron Microscopy Analysis of Malaria Hemozoin Crystals Reveals New Aspects of Crystal Growth and Elemental Composition. Cryst Growth Des. 2021. doi:10.1021/ACS.CGD.1C00087.

21. Jani D, Nagarkatti R, Beatty W, Angel R, Slebodnick C, Andersen J, et al. HDP-A Novel Heme Detoxification Protein from the Malaria Parasite. PLoS Pathog. 2008;4:e1000053.

doi:10.1371/journal.ppat.1000053.

22. Chugh M, Sundararaman V, Kumar S, Reddy VS, Siddiqui WA, Stuart KD, et al. Protein complex directs hemoglobin-to-hemozoin formation in Plasmodium falciparum. Proc Natl Acad Sci. 2013;110:1-6. doi:10.1073/pnas.1218412110/-/DCSupplemental.www.pnas.org/cgi/doi/10.1073/pnas.1218412110. 23. Sullivan DJ, Gluzman IY, Goldberg DE. Plasmodium hemozoin formation mediated by histidine-rich proteins. Science (80- ). 1996;271:219-22. doi:10.1126/science.271.5246.219.

24. Ambele MA, Sewell BT, Cummings FR, Smith PJ, Eagan T. Synthetic Hemozoin ( $\beta$-Hematin) Crystals Nucleate at the Surface of Neutral Lipid Droplets that Control Their Sizes. Cryst Growth Des. 2013;13:444252.

25. Kapishnikov S, Weiner A, Shimoni E, Guttmann P, Schneider G, Dahan-Pasternak N, et al. Oriented nucleation of hemozoin at the digestive vacuole membrane in Plasmodium falciparum. Proc Natl Acad Sci USA. 2012;109:11188-93.

26. Pisciotta JM, Coppens I, Tripathi AK, Scholl PF, Shuman J, Bajad S, et al. The role of neutral lipid nanospheres in Plasmodium falciparum haem crystallization. Biochem J. 2007;402:197-204.

27. Hempelmann E, Motta C, Hughes R, Ward S a., Bray PG. Plasmodium falciparum: Sacrificing membrane to grow crystals? Trends Parasitol. 2003;19:23-6.

28. Sullivan DJ. Theories on malarial pigment formation and quinoline action. Int J Parasitol. 2002;32:164553. doi:10.1016/S0020-7519(02)00193-5.

29. Flammersfeld A, Panyot A, Yamaryo-Botté Y, Aurass P, Przyborski JM, Flieger A, et al. A patatin-like phospholipase functions during gametocyte induction in the malaria parasite Plasmodium falciparum. Cell Microbiol. 2020;22:e13146. doi:10.1111/CMI.13146.

30. Singh P, Alaganan A, More KR, Lorthiois A, Thiberge S, Gorgette O, et al. Role of a patatin-like phospholipase in Plasmodium falciparum gametogenesis and malaria transmission. Proc Natl Acad Sci. 2019;116:17498-508. doi:10.1073/PNAS.1900266116.

31. Sheokand PK, Yamaryo-Botté Y, Thakur V, Banday MM, Asad M, Botté CY, et al. A Plasmodium falciparum lysophospholipase regulates fatty acid acquisition for membrane biogenesis to enable schizogonic asexual division. bioRxiv. 2021;:2021.07.01.450682. doi:10.1101/2021.07.01.450682. 32. A F, C L, A F, G P. Phospholipases during membrane dynamics in malaria parasites. Int J Med Microbiol. 2018;308:129-41. doi:10.1016/J.IJMM.2017.09.015. 
